\title{
COVID 19 - Concerns for the Intensive Care Physician- A Review
}

Dr. Padmakumar V Arayamparambil ${ }^{1 *}$, Mrs. Deepa C Velayudhan ${ }^{1}$

\begin{tabular}{cl}
${ }^{1}$ Department of Critical Care Medicine, Fortis Hospital Bannerghatta Road, 154/9, Opp. IIM-B, Bangalore-560076, Karnataka, India \\
\hline $\begin{array}{l}\text { Abstract: COVID-19 is most well-known for causing respiratory pathology. It can also result } \\
\text { in other organ involvement. These include thrombotic complications like myocardial infarction } \\
\text { and stroke. Cardiac arrhythmias, acute kidney injury, gastrointestinal symptoms, hepatocellular } \\
\text { injury, pancreatitis, neurologic disorders including demyelination, endocrine issues like } \\
\text { Accepted: } 27.02 .2021 .2021\end{array}$ \\
Pyberglycemia and ketosis have been reported. Individually and in combination, these can add \\
to mortality and morbidity. This review is primarily focussing on the potential life threatening \\
problems that physicians can encounter during the course of COVID 19 patients' stay in \\
intensive care unit. Electronic literature search was done to study COVD-19 and its \\
pathophysiology, different organ involvement other than lungs, ICU management and \\
mortality. The search engines used to conduct the electronic literature searches were PubMed, \\
PubMed Central, Google Scholar and CAS. A combination of keywords was used to make the \\
searches such as COVID-19 AND (Pathology OR Pathophysiology OR Complications OR \\
Organ failure OR Intensive care OR Risk factors OR Mortality).The articles published in \\
English language between the years 2019 and 2020 were considered in the review. Few cross \\
references of previous years were also reviewed and included. The findings of these studies \\
were synthesized into a narrative review.
\end{tabular}

Keywords: COVID-19, Pathophysiology, Complications, Organ failure, Intensive care, Risk factors, Mortality.

Copyright (C) 2021 The Author(s): This is an open-access article distributed under the terms of the Creative Commons Attribution 4.0 International License (CC BY-NC 4.0) which permits unrestricted use, distribution, and reproduction in any medium for non-commercial use provided the original author and source are credited.

\section{INTRODUCTION}

Coronavirus Disease 2019 (COVID-19) is the third coronavirus infection in two decades, after Severe Acute Respiratory Syndrome (SARS) and Middle East Respiratory Syndrome (MERS) [1]. The COVID-19 pandemic has seen a surge of patients with Acute Respiratory Distress Syndrome (ARDS) in intensive care units across the globe. In the initial stage of the pandemic, mortality was high due to pneumonia, ARDS and respiratory failure. COVID-19 is most well-known for causing respiratory pathology. It can also result in other organ involvement.

\section{Pathophysiology}

SARS-CoV-2 virus has receptor recognition capability similar to other virulent corona viruses such as SARS-CoV, responsible for the SARS epidemic of 2003 [2-4]. The virus' spike protein facilitates its entry into target cells. The spike subunit of SARS-CoV and SARS-CoV-2 engage ACE2 (Angiotensin Converting Enzyme 2) as an entry receptor (Fig1). Mechanisms that lead to multi-organ injury due SARS-CoV-2 infection include direct viral toxicity, endothelial cell damage and thromboinflammation, dysregulation of both the immune system and the renin-angiotensin-aldosterone system (RAAS) (Fig.1). 


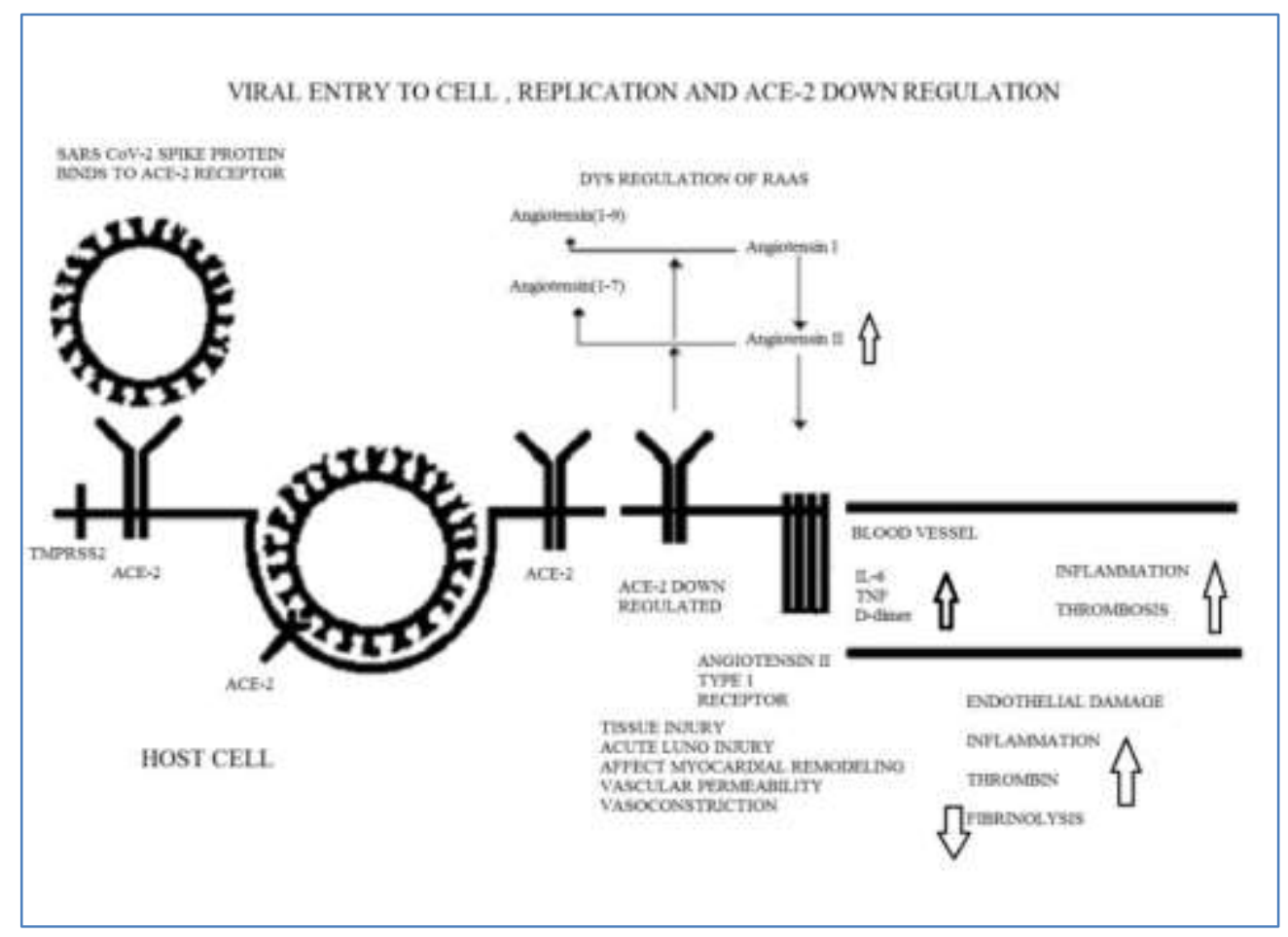

ACE 2 expression has been reported in histopathological studies in renal $[5,7]$ myocardial $[5$, 8], neurologic [5], pharyngeal [5] and gastrointestinal [9] tissues. Viral RNA was isolated less commonly from urine and blood [6].

Expression of ACE2 and TMPRSS2 (Transmembrane Protease Serine 2) was seen in lung alveolar epithelial type II cells, nasal goblet secretory cells, cholangiocytes, colonocytes, esophageal keratinocytes, gastrointestinal epithelial cells, pancreatic $\beta$-cells, and renal proximal tubules and podocytes $[5,10]$.

\section{Endothelial cell damage and thrombosis}

Endothelial cell damage by ACE2-mediated entry of SARS-CoV-2, leading to inflammation and progress to a prothrombotic state are the proposed pathophysiological mechanisms of COVID-19 [11-13]. Arterial and venous endothelium of several organs [11, 14] has ACE2 protein receptors as explained earlier.

\section{Dysregulation of the immune response}

Cytokine release syndrome, characterised by dysregulated immune response (over activation of immunity) is the hallmark of severe COVID-19 [15]. High serum inflammatory markers such as ESR (Erythrocyte Sedimentation Rate), C-reactive protein, LDH (Lactate Dehydrogenase), ferritin, D-dimer and fibrinogen are associated with severe disease and mortality in patients [16-18].

In about $30 \%$ of intensive care patients in China [19] and Netherlands [20], thrombotic complications were reported. Acute myocardial infarction (MI), acute limb ischemia and stroke were noted in studies from the USA, Italy and France [2124].

High rates of thromboembolic events were reported in critically ill patients with COVID-19 (17$22 \%$ ), despite their having received prophylactic anticoagulation [22, 25, 26].

Severe COVID leads to more inflammation, endothelial damage and activation of prothrombotic state than other viral illnesses [27, 28].

\section{Respiratory system}

COVID -19 infections can cause problems ranging from mild upper respiratory tract symptoms to life-threatening viral pneumonia [29]. Patients with severe Covid-19 progressively become hypoxemic requiring ICU admission and mechanical ventilatory support.

Chest CT imaging of patients with pneumonia has shown peripheral lung ground-glass opacities fulfilling the Berlin criteria for ARDS [30].

Progressive respiratory failure is the primary cause of death in severe disease. In a small autopsy case series, it was found that microthrombsis of alveolar capillaries and vascular angiogenesis distinguished the pulmonary pathophysiology of Covid-19 from that of equally severe influenza virus infection [11].

\section{Cardiovascular system}

Cardiovascular effects include myocardial injury, Acute Coronary Syndrome (ACS), cardiomyopathy, arrhythmia and cardiogenic shock. The pathophysiology is probably multifactorial. Cardiac 
myocytes, fibroblasts, endothelial cells and smoothmuscle cells [31] have high expression of ACE2, which can facilitate virus attachment.

Causes of myocardial damage, not specific to COVID-19, include severe ischemia or MI in patients with pre-existing coronary artery disease, Takotsubo, tachycardia-induced cardiomyopathy and myocardial stunning.

\section{Renal system}

Renal dysfunction (Acute Kidney Injury) is common with COVID-19 and is associated with mortality $[32,33]$. Patho physiologically SARS-CoV-2 may directly infect renal cells, which is a possibility supported by histopathology findings and the presence of ACE2 receptors [34]. Histopathological findings include prominent acute tubular injury, diffuse erythrocyte aggregation and obstruction in peritubular and glomerular capillary loops [5, 7]. Viral inclusion particles in glomerular capillary endothelial cells suggest that micro vascular dysfunction is secondary to endothelial damage [13]. As in the case of other influenza viruses, cytokine storm [35] adds insult to injury.

Other etiologies of AKI, including ARDS, rhabdomyolysis, volume depletion and interstitial nephritis also need to be considered [36].

\section{Gastro Intestinal Tract (GIT) and hepato biliary system}

In $14-53 \%$ of critically ill COVID-19 patients, hepatocellular injury is seen [16, 37]. Transaminitis was usually less than five times the upper limit of normal.

Direct damage to the bile duct can be caused by this virus as it can bind to ACE2 on cholangiocytes [38]. Hyper inflammation with cytokine storm and hypoxia are other potential causes of hepatocellular damage [39]. Drug-induced transaminitis, secondary to the usage of Remdesivir, Lopinavir and Tocilizumab was also reported $[39,40]$.

\section{Endocrine and metabolic effects}

A wide spectrum of abnormalities including worsening hyperglycemia, euglycemic ketosis, and classic diabetic ketoacidosis were seen. In a retrospective study from China, of 658 patients hospitalized with COVID-19, 6.4\% were presented with ketosis [41]. Studies from China and Italy demonstrated an association of underlying diabetes with severe illness and death $[42,43]$.

A more severe disease course was noted in diabetics, which may be attributable to hyperglycemia and ketosis. High cytokine levels may lead to impairment in pancreatic $\beta$-cell function and lead to apoptosis, which can contribute to insulin deficiency
[44]. ACE2 expression has been reported in the endocrine pancreas $[45,46]$.

Similar with SARS-CoV, direct binding of SARS-CoV-2 to ACE2 on $\beta$-cells might contribute to insulin deficiency and hyperglycemia [45]. Severe pancreatitis was also reported. Obesity [47] and diabetes [48] are risk factors for severe illness.

\section{Nervous system}

About 6\% incidence of stroke [23, 49] is reported with severe COVID-19. Guillain-Barré syndrome has also been reported in some patients [50, 51]. Meningoencephalitis [52], Posterior Reversible Encephalopathy Syndrome (PRES) [53] and acute necrotizing encephalopathy have been described in case reports $[54,55]$.

Coronavirus that causes MERS have known neuroinvasive and neurotropic abilities [56, 57]. SARSCoV-2 may access the central nervous system via the nasal mucosa, lamina cribrosa, and olfactory bulb. This can lead to meningoencephalitis.

Cytokine storm with its proinflammatory and prothrombotic cascade affects brain vasculature and the blood-brain barrier (often seen in severe cases).

\section{INTENSIVE CARE MANAGEMENT Airway and Breathing}

COVID-19 patients requiring ICU admission are usually very hypoxic, needing some form of ventilator assistance. Approximately $5 \%$ of the patients who contract COVID-19 require admission to ICUs [58]. During the initial phase of the pandemic, most of the hypoxic patients were intubated early and Non Invasive modalities like HFNC (High Flow Nasal Cannula) and NIV (Non Invasive Ventilation) were not considered due to concerns of infection spread (aerosols). The concerns about aerosol dispersion had led to calls for early intubation [59]. With time, more evidence has emerged about the safety of Non Invasive Ventilation. With experience, physicians realized that mortality of invasively ventilated patients was high and it was not easy to extubate many of these patients.

Among patients with COVID-19 with ARDS, Gattinoni et al. [60-62] have described an "L" phenotype (for low elastance) in patients who demonstrated relatively preserved respiratory system compliance of $>50 \mathrm{~mL} / \mathrm{cm} \mathrm{H}_{2} \mathrm{O}$ with focal areas of ground-glass opacity on CT scanning. In contrast, low compliance (" $\mathrm{H}$ " phenotype-for high elastance), is typically seen in non-COVID-19 patients with ARDS.

A number of studies have compared HFNC with NIV and mask oxygen. HFNC has been shown to be more comfortable and better tolerated [63]. Surviving Sepsis/Society of Critical Care Medicine guideline [64] advocates it as a first-line approach. 
Patients on Non Invasive modalities will require very close monitoring in ICU. Patients who are rapidly deteriorating due to worsening hypoxemia, hypercarbia and acidosis will require invasive ventilator support.

Currently there are no studies addressing mechanical ventilation strategies in COVID-19 patients. Mechanically ventilated patients with COVID-19 should be managed similar to other patients with acute respiratory failure in the ICU [64]. A strong recommendation is to use low Tidal Volume (VT: 4$8 \mathrm{~mL} / \mathrm{kg}$ predicted body weight) when ventilating patients.

While mechanical ventilation is a potentially life-saving intervention, it can worsen lung injury and ventilator-induced lung injury (VILI) can contribute to multiorgan failure in patients with ARDS [65]. One of the main ventilator strategies to minimize VILI is low VT ventilation.

\section{Circulation and hemodynamics}

Hemodynamic monitoring and support for COVD -19 patients should be similar to any other critical patient in ICU. The prognosis of patients with COVID-19 with shock has not been systematically reported. In a study of 150 patients from 2 hospitals in Wuhan, China, shock was a major reason for death in $40 \%$, and partly be due to fulminant myocarditis[66].

Patients with shock will need dynamic parameters like skin temperature, capillary refilling time and/or serum lactate measurement over static parameters in order to assess fluid responsiveness [64]. For the acute resuscitation of adults with COVID-19 with shock, a conservative over a liberal fluid strategy is recommended (based on data extrapolated from critically ill patients with sepsis or ARDS).

After adequate fluid resuscitation, for adults with COVID-19 and shock, Norepinephrine is recommended as the first-line vasoactive agent. Vasopressin can be added as a second-line agent, along with titrating Norepinephrine dose, if target mean arterial pressure (MAP of $60-65 \mathrm{mmHg}$ ) cannot be achieved by Norepinephrine alone[64].

For patients in shock with evidence of cardiac dysfunction and persistent hypo perfusion, despite fluid resuscitation and norepinephrine, adding dobutamine should be considered over increasing norepinephrine dose [64]. Low-dose corticosteroid therapy is recommended for refractory shock [64].

\section{Microvascular thrombosis and ischaemia}

COVID -19 infection is known to produce microvasular thrombosis and ischeamia. Peripheral ischaemia involving digits and limbs are reported. Shock with hypo perfusion along with vasopressors will add to the problem .Critical care physicians should be vigilant about this dreaded complication [67].

\section{Renal}

Severe COVID-19 pneumonia patients can develop Acute Kidney Injury due to multiple reasons. Apart from the direct insult of the virus on kidneys, other causes like rhabdomyolysis, volume depletion and interstitial nephritis need to be considered. Due to severe pneumonia and ARDS, clinicians tend to adopt a conservative fluid strategy which in turn can worsen renal function. Hemodynamic instability and sepsis will adversely affect renal function and increase the recovery time and mortality $[32,33]$. ICU team needs to take a cautious approach to prevent intravascular volume depletion and maintain hemodynamic stability. Cytokine storm [35] adds to kidney injury.

The care strategy for patients with COVID-19 in the ICU remains mainly supportive. With high incidence of kidney involvement in COVID-19, it is important to support kidney function with all possible treatment options.

Following KDIGO supportive care guideline (e.g., avoidance of nephrotoxins, regular monitoring of serum creatinine and urine output, consideration of haemodynamic monitoring) in critically ill patients with kidney involvement is likely to reduce the occurrence and severity of AKI in COVID-19 [68].

If conservative management fails, Renal Replacement Therapy (RRT) should be considered in patients with volume overload, especially those with refractory hypoxemia. Other indications for RRT are oliguria, hyperkalemia, acidosis and azotaemia. Continuous RRT (CRRT) is the preferred modality in haemodynamically unstable patients with COVID-19 [69].

\section{Gastro Intestinal Tract (GIT) and hepatobiliary system}

Apart from direct viral invasion and damage to GIT causing nausea, vomiting and diarrhoea, potentially lethal complication like mesenteric ischemia can happen with severe COVID -19 infections. Histopathological evidence of diffuse endothelial inflammation in the submucosal vessels of the small intestine from patients with COVID-19 and mesenteric ischemia suggests microvascular small-bowel injury [13]. Unexplained lactic acidosis and diarrhoea should arouse high index of suspicion.

Even though incidence of GI bleed was not reported higher than in general ICU population, it is a potential complication which needs specific attention, since most ICU patients with COVID -19 will be on high dose anticoagulation and steroids. Hemodynamic instability and shock will add to the risk of GI bleed. 
Viral invasion and injury to biliary tree and hepatocellular damage has been documented in critically ill patients [18]. Transaminitis, secondary to anti-viral drugs (Remdesivir) and Tocilizumab also need to be monitored closely.

Pancreatitis is another dreaded complication seen associated with COVID-19 infection. Symptoms can range from mild to potentially life threatening disease.

\section{Nervous system}

Acute incidence of stroke is seen in COVID19 [23, 49]. It is important to watch for neurological deterioration in severe COVID-19 pneumonia patients requiring invasive mechanical ventilator support. Most of these patients will require deep sedation and Neuro Muscular Blocking agents to facilitate ventilation. This in turn will make motor assessment impossible. Meningoencephalitis [52], hemorrhagic posterior reversible encephalopathy syndrome [53] and acute necrotizing encephalopathy, including the brainstem and basal ganglia, have been described in case reports $[54,55]$. Some of these neurological complications alone can lead to fatal outcome. Other neurological sequalae of critical illness are neuropathy and myopathy (high incidence is expected due to requirement of Neuro Muscular Blocking agents and Steroids) which in turn can delay the weaning from mechanical ventilation.

\section{Endocrine and metabolic effects}

A wide spectrum of abnormalities of glucose metabolism is seen in patients with COVID-19, including worsening hyperglycemia, euglycemic ketosis and classic diabetic ketoacidosis [41]. Glycemic control can further worsen by critical illness and steroid use. Such patients in the ICU will require continuous Insulin infusions and hourly blood glucose monitoring. Fluid management can become challenging as fluid overload can worsen hypoxemia. Adrenal insufficiency has to be kept in mind as most hypoxic patients will need steroids for longer period (Watch after 'taper and stop').

\section{Sepsis}

Secondary infection and sepsis is a challenge for patients who require invasive mechanical ventilator support. Most of these patients will need prolonged stay in ICU and ventilation. Periodic surveillance cultures and appropriate antibiotics are recommended. Incidence of sepsis is further increased by usage of steroids and Tocilizumab. If treating team initiates empiric antimicrobials, they should assess for de-escalation daily, and re-evaluate the duration of therapy and spectrum of coverage based on the microbiology results and the patient's clinical status.

\section{Cytokine storm syndrome}

Cytokine storm syndrome is a hyper inflammatory state that is characterized by fulminant multi-organ failure and elevation of cytokine levels.
Severely ill patients with COVID-19 may have an extreme immune response leading to severe respiratory failure. In such cases, inhibition of Interleukin 6 (IL-6) may help attenuate the cytokine release syndrome by reducing cytokine concentration and acute phase reactant production [70].

Tocilizumab is a humanized immunoglobulin that functions in the immune response and blocks IL-6 receptor binding to IL-6. It has been approved for CRS and other inflammatory conditions related to IL-6 related inflammation. It has been used on experimental basis [71].

This study published recently provides strong evidence that Tocilizumab might prevent intubation and death in adults with severe COVID-19 pneumonia. These findings are also in agreement with emerging evidence that, in the setting of COVID-19-induced cytokine storm, immunosuppressive treatments might be most helpful earlier in the disease, before florid respiratory failure [72].

\section{Other supportive care}

Other supportive care includes anti-viral, anticoagulation, thromboprophylaxis, steroids and stress ulcer prophylaxis. Feeding and nutritional support is another area of importance in critical patients with COVID -19 since most of these patients are hyper catabolic.

\section{CONCLUSION}

Beyond the life-threatening pulmonary complications of SARS-CoV-2, the widespread other organ-specific pathology of COVID-19 are increasingly being recognized. Some of these are potentially life threatening by itself. It is important for the treating team to understand that COVID-19 is a multisystem disease akin to vasculitic disorders and anticipate possible complications and plan the treatment accordingly.

\section{REFERENCES}

1. Morens, D. M., Daszak, P., \& Taubenberger, J. K. (2020). Escaping Pandora's box-another novel coronavirus. New England Journal of Medicine, 382(14), 1293-1295.

2. Lan, J., Ge, J., Yu, J., Shan, S., Zhou, H., Fan, S., \& Wang, X. (2020). Structure of the SARS-CoV-2 spike receptor-binding domain bound to the ACE2 receptor. Nature, 581(7807), 215-220.

3. Shang, J., Ye, G., Shi, K., Wan, Y., Luo, C., Aihara, H., \& Li, F. (2020). Structural basis of receptor recognition by SARS-CoV2. Nature, 581(7807), 221-224.

4. Li, W., Moore, M. J., Vasilieva, N., Sui, J., Wong, S. K., Berne, M. A., \& Farzan, M. (2003). Angiotensin-converting enzyme 2 is a functional receptor for the SARS coronavirus. Nature, 426(6965), 450-454. 
5. Puelles, V. G. (2020). Multiorgan and Renal Tropism of SARS-CoV-2. $\mathrm{n}$ engl $\mathrm{j}$ med.

6. Wang, W., Xu, Y., Gao, R., Lu, R., Han, K., Wu, G., \& Tan, W. (2020). Detection of SARS-CoV-2 in different types of clinical specimens. Jama, 323(18), 1843-1844.

7. Su, H., Yang, M., Wan, C., Yi, L. X., Tang, F., Zhu, H. Y., \& Zhang, C. (2020). Renal histopathological analysis of 26 postmortem findings of patients with COVID-19 in China. Kidney international, 98(1), 219-227.

8. Tavazzi, G., Pellegrini, C., Maurelli, M., Belliato, M., Sciutti, F., Bottazzi, A., \& Arbustini, E. (2020). Myocardial localization of coronavirus in COVID19 cardiogenic shock. European journal of heart failure, 22(5), 911-915.

9. Xiao, F., Tang, M., Zheng, X., Liu, Y., Li, X., \& Shan, H. (2020). Evidence for gastrointestinal infection of SARS-CoV2. Gastroenterology, 158(6), 1831-1833.

10. Qi, F., Qian, S., Zhang, S., \& Zhang, Z. (2020). Single cell RNA sequencing of 13 human tissues identifies cell types and receptors of human coronaviruses. Biochemical and biophysical research communications, 526(1), 135-140.

11. Ackermann, M., Verleden, S. E., Kuehnel, M., Haverich, A., Welte, T., Laenger, F., \& Jonigk, D. (2020). Pulmonary vascular endothelialitis, thrombosis, and angiogenesis in Covid-19. New England Journal of Medicine, 383(2), 120-128.

12. Teuwen, L. A., Geldhof, V., Pasut, A., \& Carmeliet, P. (2020). COVID-19: the vasculature unleashed. Nature Reviews Immunology, 20(7), 389-391.

13. Varga, Z., Flammer, A. J., Steiger, P., Haberecker, M., Andermatt, R., Zinkernagel, A. S., \& Moch, H. (2020). Endothelial cell infection and endotheliitis in COVID-19. The Lancet, 395(10234), 1417-1418.

14. Hamming, I., Timens, W., Bulthuis, M. L. C., Lely, A. T., Navis, G. V., \& van Goor, H. (2004). Tissue distribution of ACE2 protein, the functional receptor for SARS coronavirus. A first step in understanding SARS pathogenesis. The Journal of Pathology: A Journal of the Pathological Society of Great Britain and Ireland, 203(2), 631-637.

15. Kim, K. D., Zhao, J., Auh, S., Yang, X., Du, P., Tang, H., \& Fu, Y. X. (2007). Adaptive immune cells temper initial innate responses. Nature medicine, 13(10), 1248-1252.

16. Zhou, F., Yu, T., Du, R., Fan, G., Liu, Y., Liu, Z., \& Cao, B. (2020). Clinical course and risk factors for mortality of adult inpatients with COVID-19 in Wuhan, China: a retrospective cohort study. The lancet, 395(10229), 1054-1062.

17. Petrilli, C. M., Jones, S. A., Yang, J., Rajagopalan, H., O’Donnell, L., Chernyak, Y. ... \& Horwitz, L. I. (2020). Factors associated with hospital admission and critical illness among 5279 people with coronavirus disease 2019 in New York City: prospective cohort study. Bmj, 369.
18. Cummings, M. J., Baldwin, M. R., Abrams, D., Jacobson, S. D., Meyer, B. J., Balough, E. M., ... \& O'Donnell, M. R. (2020). Epidemiology, clinical course, and outcomes of critically ill adults with COVID-19 in New York City: a prospective cohort study. The Lancet, 395(10239), 1763-1770.

19. Cui, S., Chen, S., Li, X., Liu, S., \& Wang, F. (2020). Prevalence of venous thromboembolism in patients with severe novel coronavirus pneumonia. Journal of Thrombosis and Haemostasis, 18(6), 1421-1424.

20. Klok, F. A., Kruip, M. J. H. A., Van der Meer, N. J. M., Arbous, M. S., Gommers, D. A. M. P. J., Kant, K. M., ... \& Endeman, H. (2020). Incidence of thrombotic complications in critically ill ICU patients with COVID-19. Thrombosis research, 191, 145-147.

21. Bangalore, S., Sharma, A., Slotwiner, A., Yatskar, L., Harari, R., Shah, B., \& Hochman, J. S. (2020). ST-segment elevation in patients with Covid-19-a case series. New England Journal of Medicine, 382(25), 2478-2480.

22. Helms, J., Tacquard, C., Severac, F., LeonardLorant, I., Ohana, M., Delabranche, X., \& Meziani, F. (2020). High risk of thrombosis in patients with severe SARS-CoV-2 infection: a multicenter prospective cohort study. Intensive care medicine, 46(6), 1089-1098.

23. Oxley, T. J., Mocco, J., Majidi, S., Kellner, C. P., Shoirah, H., Singh, I. P., \& Fifi, J. T. (2020). Large-vessel stroke as a presenting feature of Covid-19 in the young. New England Journal of Medicine, 382(20), e60.

24. Perini, P., Nabulsi, B., Massoni, C. B., Azzarone, M., \& Freyrie, A. (2020). Acute limb ischaemia in two young, non-atherosclerotic patients with COVID-19. The Lancet, 395(10236), 1546.

25. Llitjos, J. F., Leclerc, M., Chochois, C., Monsallier, J. M., Ramakers, M., Auvray, M., \& Merouani, K. (2020). High incidence of venous thromboembolic events in anticoagulated severe COVID-19 patients. Journal of Thrombosis and Haemostasis, 18(7), 1743-1746.

26. Lodigiani, C., Iapichino, G., Carenzo, L., Cecconi, M., Ferrazzi, P., Sebastian, T., \& Force, T. (2020). Venous and arterial thromboembolic complications in COVID-19 patients admitted to an academic hospital in Milan, Italy. Thrombosis research, 191, 9-14.

27. Ramacciotti, E., Agati, L. B., Aguiar, V. C., Wolosker, N., Guerra, J. C., de Almeida, R. P., ... \& Fareed, J. (2019). Zika and Chikungunya virus and risk for venous thromboembolism. Clinical and Applied Thrombosis/Hemostasis, 25, 1076029618821184.

28. Smither, S. J., O’Brien, L. M., Eastaugh, L., Woolley, T., Lever, M., Fletcher, T., ... \& Kirkman, E. (2019). Haemostatic changes in five patients infected with Ebola virus. Viruses, 11(7), 647. 
29. Chen, N., Zhou, M., Dong, X., Qu, J., Gong, F., Han, Y., \& Zhang, L. (2020). Epidemiological and clinical characteristics of 99 cases of 2019 novel coronavirus pneumonia in Wuhan, China: a descriptive study. The lancet, 395(10223), 507-513.

30. Raptis, C. A., Hammer, M. M., Short, R. G., Shah, A., Bhalla, S., Bierhals, A. J., \& Henry, T. S. (2020). Chest CT and coronavirus disease (COVID-19): a critical review of the literature to date. American Journal of Roentgenology, 215(4), 839-842.

31. Gallagher, P. E., Ferrario, C. M., \& Tallant, E. A. (2008). Regulation of ACE2 in cardiac myocytes and fibroblasts. American Journal of PhysiologyHeart and Circulatory Physiology, 295(6), H2373$\mathrm{H} 2379$.

32. Naicker, S., Yang, C. W., Hwang, S. J., Liu, B. C., Chen, J. H., \& Jha, V. (2020). The novel coronavirus 2019 epidemic and kidneys. Kidney International, 97(5), 824-828.

33. Cheng, Y., Luo, R., Wang, K., Zhang, M., Wang, Z., Dong, L., \& Xu, G. (2020). Kidney disease is associated with in-hospital death of patients with COVID-19. Kidney international, 97(5), 829-838.

34. Su, H., Yang, M., Wan, C., Yi, L. X., Tang, F., Zhu, H. Y., \& Zhang, C. (2020). Renal histopathological analysis of 26 postmortem findings of patients with COVID-19 in China. Kidney international, 98(1), 219-227.

35. Iwasaki, A., \& Pillai, P. S. (2014). Innate immunity to influenza virus infection. Nature Reviews Immunology, 14(5), 315-328.

36. Peerapornratana, S., Manrique-Caballero, C. L., Gómez, H., \& Kellum, J. A. (2019). Acute kidney injury from sepsis: current concepts, epidemiology, pathophysiology, prevention and treatment. Kidney international, 96(5), 1083-1099.

37. Guan, W. J., Ni, Z. Y., Hu, Y., Liang, W. H., Ou, C. Q., He, J. X., ... \& Zhong, N. S. (2020). Clinical characteristics of coronavirus disease 2019 in China. New England journal of medicine, 382(18), 1708-1720.

38. Zhang, C., Shi, L., \& Wang, F. S. (2020). Liver injury in COVID-19: management and challenges. The lancet Gastroenterology \& hepatology, 5(5), 428-430.

39. Cao, B., Wang, Y., Wen, D., Liu, W., Wang, J., Fan, G., ... \& Wang, C. (2020). A trial of lopinavirritonavir in adults hospitalized with severe Covid19. New England Journal of Medicine.

40. Bangash, M. N., Patel, J., \& Parekh, D. (2020). COVID-19 and the liver: little cause for concern. The lancet. Gastroenterology \& hepatology, 5(6), 529.

41. Li, J., Wang, X., Chen, J., Zuo, X., Zhang, H., \& Deng, A. (2020). COVID-19 infection may cause ketosis and ketoacidosis. Diabetes, Obesity and Metabolism, 22(10), 1935-1941.

42. Onder, G., Rezza, G., \& Brusaferro, S. (2020). Case-fatality rate and characteristics of patients dying in relation to COVID-19 in Italy. Jama, 323(18), 1775-1776.

43. Wu, Z., \& McGoogan, J. M. (2020). Characteristics of and important lessons from the coronavirus disease 2019 (COVID-19) outbreak in China: summary of a report of 72314 cases from the Chinese Center for Disease Control and Prevention. Jama, 323(13), 1239-1242.

44. Eizirik, D. L., \& Darville, M. I. (2001). Beta-cell apoptosis and defense mechanisms: lessons from type 1 diabetes. Diabetes, 50( suppl 1), S64.

45. Yang, J. K., Lin, S. S., Ji, X. J., \& Guo, L. M. (2010). Binding of SARS coronavirus to its receptor damages islets and causes acute diabetes. Acta diabetologica, 47(3), 193-199.

46. Harmer, D., Gilbert, M., Borman, R., \& Clark, K. L. (2002). Quantitative mRNA expression profiling of ACE 2, a novel homologue of angiotensin converting enzyme. FEBS letters, 532(1-2), 107 110 .

47. McClean, K. M., Kee, F., Young, I. S., \& Elborn, J. S. (2008). Obesity and the lung: 1 . Epidemiology. Thorax, 63(7), 649-654.

48. Hibbert, K., Rice, M., \& Malhotra, A. (2012). Obesity and ARDS. Chest, 142(3), 785-790.

49. Yaghi, S., Ishida, K., Torres, J., Mac Grory, B., Raz, E., Humbert, K., \& Frontera, J. (2020). SARSCoV-2 and stroke in a New York healthcare system. Stroke, 51(7), 2002-2011.

50. Zhao, H., Shen, D., Zhou, H., Liu, J., \& Chen, S. (2020). Guillain-Barré syndrome associated with SARS-CoV-2 infection: causality or coincidence?. The Lancet Neurology, 19(5), 383384.

51. Toscano, G., Palmerini, F., Ravaglia, S., Ruiz, L., Invernizzi, P., Cuzzoni, M. G., ... \& Micieli, G. (2020). Guillain-Barré syndrome associated with SARS-CoV-2. New England Journal of Medicine, 382(26), 2574-2576.

52. Helms, J., Kremer, S., Merdji, H., Clere-Jehl, R., Schenck, M., Kummerlen, C., \& Meziani, F. (2020). Neurologic features in severe SARS-CoV-2 infection. New England Journal of Medicine, 382(23), 2268-2270.

53. Franceschi, A. M., Ahmed, O., Giliberto, L., \& Castillo, M. (2020). Hemorrhagic posterior reversible encephalopathy syndrome as a manifestation of COVID-19 infection. American Journal of Neuroradiology, 41(7), 1173-1176.

54. Moriguchi, T., Harii, N., Goto, J., Harada, D., Sugawara, H., Takamino, J., ... \& Shimada, S. (2020). A first case of meningitis/encephalitis associated with SARS-Coronavirus2. International Journal of Infectious Diseases, 94, 55-58.

55. Poyiadji, N., Shahin, G., Noujaim, D., Stone, M., Patel, S., \& Griffith, B. (2020). COVID-19associated acute hemorrhagic necrotizing encephalopathy: imaging features. Radiology, 296(2), E119-E120. 
56. Desforges, M., Le Coupanec, A., Stodola, J. K., Meessen-Pinard, M., \& Talbot, P. J. (2014). Human coronaviruses: viral and cellular factors involved in neuroinvasiveness and neuropathogenesis. Virus research, 194, 145-158.

57. Li, Y. C., Bai, W. Z., \& Hashikawa, T. (2020). The neuroinvasive potential of SARS-CoV2 may play a role in the respiratory failure of COVID-19 patients. Journal of medical virology, 92(6), 552555.

58. Wu, Z., \& McGoogan, J. M. (2020). Characteristics of and important lessons from the coronavirus disease 2019 (COVID-19) outbreak in China: summary of a report of 72314 cases from the Chinese Center for Disease Control and Prevention. Jama, 323(13), 1239-1242.

59. Cheung, J. C. H., Ho, L. T., Cheng, J. V., Cham, E. Y. K., \& Lam, K. N. (2020). Staff safety during emergency airway management for COVID-19 in Hong Kong. The Lancet. Respiratory Medicine, 8(4), e19.

60. Gattinoni, L., Chiumello, D., \& Rossi, S. (2020). COVID-19 pneumonia: ARDS or not?.

61. Gattinoni, L., Chiumello, D., Caironi, P., Busana, M., Romitti, F., Brazzi, L., \& Camporota, L. (2020). COVID-19 pneumonia: different respiratory treatments for different phenotypes?

62. Marini, J. J., \& Gattinoni, L. (2020). Management of COVID-19 respiratory distress. Jama, 323(22), 2329-2330.

63. Spoletini, G., Alotaibi, M., Blasi, F., \& Hill, N. S. (2015). Heated humidified high-flow nasal oxygen in adults. Chest, 148(1), 253-261.

64. Alhazzani, W., Møller, M. H., Arabi, Y. M., Loeb, M., Gong, M. N., Fan, E., \& Rhodes, A. (2020). Surviving Sepsis Campaign: guidelines on the management of critically ill adults with Coronavirus Disease 2019 (COVID-19). Intensive care medicine, 46(5), 854-887.
65. Slutsky, A. S., \& Ranieri, V. M. (2013). Ventilatorinduced lung injury. New England Journal of Medicine, 369(22), 2126-2136.

66. Ruan, Q., Yang, K., Wang, W., Jiang, L., \& Song, J. (2020). Clinical predictors of mortality due to COVID-19 based on an analysis of data of 150 patients from Wuhan, China. Intensive care medicine, 46(5), 846-848.

67. Bellosta, R., Luzzani, L., Natalini, G., Pegorer, M. A., Attisani, L., Cossu, L. G., \& Piffaretti, G. (2020). Acute limb ischemia in patients with COVID-19 pneumonia. Journal of vascular surgery, 72(6), 1864-1872.

68. Kidney Disease: Improving Global Outcomes (KDIGO) Acute Kidney Injury Work Group KDIGO clinical practice guideline for acute kidney injury. (2012). Kidney Int Suppl, 2:1-138

69. Ronco, C., Reis, T., \& Husain-Syed, F. (2020). Management of acute kidney injury in patients with COVID-19. The Lancet Respiratory Medicine.

70. Chen, X., Zhao, B., Qu, Y., Chen, Y., Xiong, J., Feng, Y., \& Li, F. (2020). Detectable serum SARSCoV-2 viral load (RNAaemia) is closely correlated with drastically elevated interleukin 6 (IL-6) levels in critically ill COVID-19 patients. Clinical infectious diseases.

71. Guaraldi, G., Meschiari, M., Cozzi-Lepri, A., Milic, J., Tonelli, R., Menozzi, M., \& Mussini, C. (2020). Tocilizumab in patients with severe COVID-19: a retrospective cohort study. The Lancet Rheumatology, 2(8), e474-e484.

72. Capra, R., De Rossi, N., Mattioli, F., Romanelli, G., Scarpazza, C., Sormani, M. P., \& Cossi, S. (2020). Impact of low dose tocilizumab on mortality rate in patients with COVID-19 related pneumonia. European journal of internal medicine, 76, 31-35.

Cite this article: Padmakumar V Arayamparambil \& Deepa C Velayudhan (2021). COVID 19 - Concerns for the Intensive Care Physician- A Review. EAS J Anesthesiol Crit Care, 3(2), 10-17. 